\title{
Endoscopic management of ingested foreign bodies in children: A retrospective review of cases, and review of the literature*
}

\author{
Tariq O. Abbas", Noora Al Shahwani, Mansour Ali \\ Department of Pediatric Surgery, Hamad General Hospital, Doha, Qatar \\ Email: "tariq2c@hotmail.com
}

Received 20 November 2013; revised 15 December 2013; accepted 22 December 2013

Copyright (C) 2013 Tariq O. Abbas et al. This is an open access article distributed under the Creative Commons Attribution License, which permits unrestricted use, distribution, and reproduction in any medium, provided the original work is properly cited.

\begin{abstract}
Background: Foreign body (FB) ingestion by children is a common problem worldwide. Management may include endoscopic removal. This paper describes the clinical findings, sites and types of FBs, and outcomes in children who underwent endoscopic management of ingested FBs at our institution. The published literature regarding the management of FB ingestion in children is also reviewed. Methods: We retrospectively reviewed the records of all patients aged $<14$ years who underwent endoscopic management of gastrointestinal FBs between July 2002 and June 2012 (47 patients) and tracheobronchial FBs between December 2010 and June 2012 (17 patients) at our institution. Patient characteristics, clinical findings, sites and types of FBs, and outcomes were recorded. Results: The 47 patients with gastrointestinal FBs included 29 males and 18 females with a mean age of 3.5 years. The most common symptoms were difficulty with swallowing and vomiting in 16 patients (34\%), chest pain in $10(21 \%)$, and coughing and breathing difficulty in 7 (15\%). The most common FB site was the esophagus (36 patients). Most gastrointestinal FBs were metallic, with coins being the most common. Endoscopic removal was successful in $\mathbf{4 3}$ patients. The 17 patients with tracheobronchial foreign bodies included 9 males and 8 females with a mean age of 3.2 years. The most common symptoms were breathing difficulty in 12 patients $(71 \%)$ and coughing in $3(18 \%)$. The most common tracheobronchial FBs were nuts (10 patients). Bronchoscopic
\end{abstract}

${ }^{*}$ Conflicts of interest: Tariq O. Abbas, Noora Al Shahwani, and Mansour Ali have no conflicts of interest or financial ties to disclose. Author Contributions: TA contributed in design and manuscript preparation, NA contributed in data collection with GG; MA supervised the study and assisted in revising the final manuscript.

${ }^{\#}$ Corresponding author. removal was successful in all 17 patients. Conclusions: Coins were the most common gastrointestinal FBs, and nuts were the most common tracheobronchial FBs. Clinical presentations were variable, and a high index of suspicion is necessary. Endoscopic removal is safe and effective, and early diagnosis and management result in favorable outcomes.

Keywords: Foreign Body Ingestion; Pediatric Endoscopy; Coin; Aspiration

\section{INTRODUCTION}

Foreign body (FB) ingestion by children is a common problem worldwide, as children tend to put a variety of objects in their mouths from the age of 6 months. Types of ingested FBs vary among communities according to feeding habits and sociocultural factors [1-3].

It has been reported that $80 \%-90 \%$ of FBs that come to medical attention pass through the gastrointestinal tract uneventfully, $10 \%-20 \%$ require endoscopic removal, and $1 \%$ or less require surgery [4]. Although FB ingestion causes serious morbidity in less than $1 \%$ of cases, it is the cause of approximately 1500 deaths per year in the United States $[5,6]$.

Most ingested FBs in children can safely be removed by endoscopy under general anesthesia [7,8]. Pediatric surgeons are usually the primary physicians managing these children. Otolaryngologists, radiologists, and pediatric gastroenterologists are also commonly involved in the care of these patients $[9,10]$.

The numbers of children presenting with FB ingestion and with associated morbidity and mortality are increasing. Early diagnosis and appropriate treatment are important to ensure good outcomes.

This study retrospectively reviewed the clinical findings, sites and types of FBs, and outcomes of children 
who underwent endoscopic management of ingested FBs at our institution. We also reviewed the current literature regarding the management of FB ingestion in children.

\section{PATIENTS AND METHODS}

The medical records of all patients aged $<14$ years who underwent endoscopic management of gastrointestinal FBs between July 2002 and June 2012 (47 patients) and tracheobronchial FBs between December 2010 and June 2012 (17 patients) in the Department of Pediatric Surgery at Hamad General Hospital, Doha, Qatar were retrospectively reviewed. Patient characteristics and clinical findings including age, gender, site of FB, type of FB, clinical presentation, radiological findings, and outcomes were recorded. The study protocol was approved by the institutional ethics committee of the Medical Research Centre at Hamad Medical Corporation.

The indications for endoscopic management of gastrointestinal FBs at our hospital were: 1) gastrointestinal symptoms with a high suspicion of FB ingestion, 2) a coin in the esophagus after 6 hours of observation in an asymptomatic patient, 3) ingestion of a sharp FB, and 4) ingestion of a FB longer than $3-4 \mathrm{~cm}$. All endoscopic procedures were performed under general anesthesia in the operating room. Coins located in the proximal esophagus were removed using a laryngoscope and Magill forceps. Other gastrointestinal FBs were removed using a rigid esophagoscope (Storz) equipped with an optical telescope (Hopkins) and alligator or peanut-type forceps. The size and length of instruments were chosen according to the age and weight of the patient.

Bronchoscopy was performed in children with a witnessed choking event followed by a period of coughing. Bronchoscopy was performed by a pediatric respirologist, and if a FB was identified it was removed by a pediatric surgeon using a rigid bronchoscope (Storz) equipped with an optical telescope (Hopkins) and alligator or peanut-type forceps. The size and length of instruments were chosen according to the age and weight of the patient.

\section{RESULTS}

\subsection{Gastrointestinal Foreign Bodies}

The 47 patients with gastrointestinal FBs included 29 males and 18 females with a mean age of 3.5 years (range, 3 months to 13 years). Thirty-four patients (72\%) were aged $0-4$ years, $12(26 \%)$ were aged 5 - 9 years, and $1(2 \%)$ was aged $10-13$ years. Foreign body ingestion was witnessed in 16 of these patients, and suspected in the rest. Symptoms included difficulty with swallowing and vomiting in 16 patients (34\%), chest pain in 10 $(21 \%)$, coughing and breathing difficulty in $7(15 \%)$, and fever in $5(11 \%)$. Fifteen patients $(32 \%)$ were asymptomatic at presentation. Twenty-eight patients $(60 \%)$ pre- sented within 6 hours after the onset of symptoms, five (11\%) presented after 6 - 24 hours, four $(9 \%)$ presented after 1 - 7 days, and one (2\%) presented after 1 month. The time of ingestion was unknown in nine patients $(19 \%)$. The distribution of symptoms according to the time of presentation is shown in Figure 1.

Physical examination revealed stridor in one patient, and known situs inversus in one patient. The other patients did not have any abnormalities on physical examination. Posteroanterior chest X-ray findings were available in the records of 43 patients. A radio-opaque FB was detected in the esophagus in 36 patients, at the gastroesophageal junction in 1 patient, and in the stomach in 1 patient. A lung opacity consistent with aspiration was also detected in one of these patients.

Endoscopic FB removal was attempted in 46 of the 47 patients and was successful in 43 patients, using rigid endoscopy in 41 patients, laryngoscopy in 1 patient, and flexible endoscopy in 1 patient. In the remaining three patients, the foreign body was not found on endoscopy and follow-up X-ray confirmed passage.

Most gastrointestinal FBs were metallic. Ingested FBs were coins in 24 patients, button batteries in 4 , earrings in 2, a hairpin in 1, a key in 1, an earphone in 1, a marble in 1 , and a button in 1 . The type of FB was not specified in the other patients.

The mean duration of endoscopic or surgical procedures was $48 \mathrm{~min}$ and the mean postoperative hospital stay was 2.6 days. One 2-year-old patient who presented with a button battery in the upper esophagus subsequently developed a long esophageal stricture that was treated with frequent balloon dilatations (Figure 2).

\subsection{Tracheobronchial Foreign Bodies}

The 17 patients with tracheobronchial foreign bodies included 9 males and 8 females, with a mean age of 3.2 years (range, 11 months to 11 years). Twelve patients $(86 \%)$ were aged 0 - 4 years, three $(21 \%)$ were aged $5-9$ years, and two (14\%) were aged $10-13$ years. Foreign

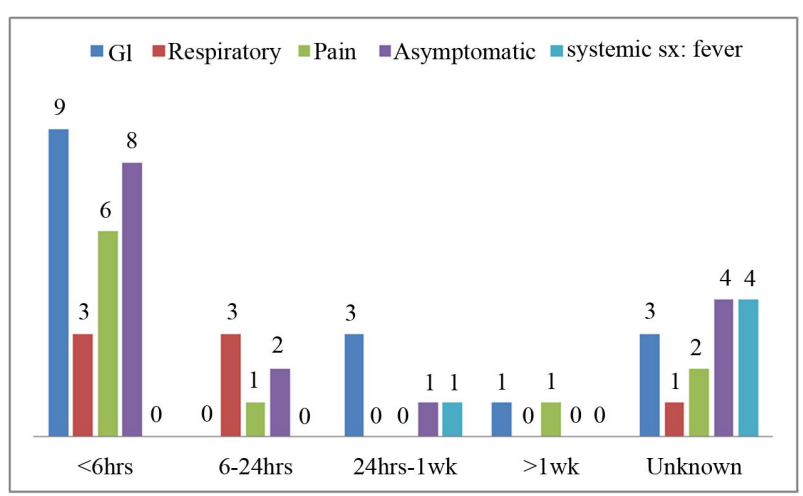

Figure 1. Symptoms in patients with gastrointestinal foreign bodies according to the duration of lodgment. 


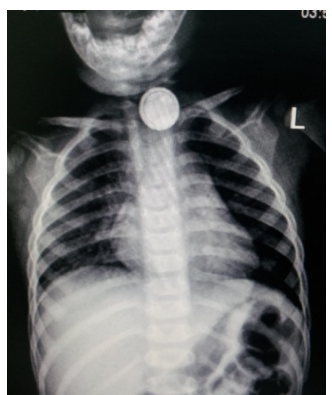

(a)

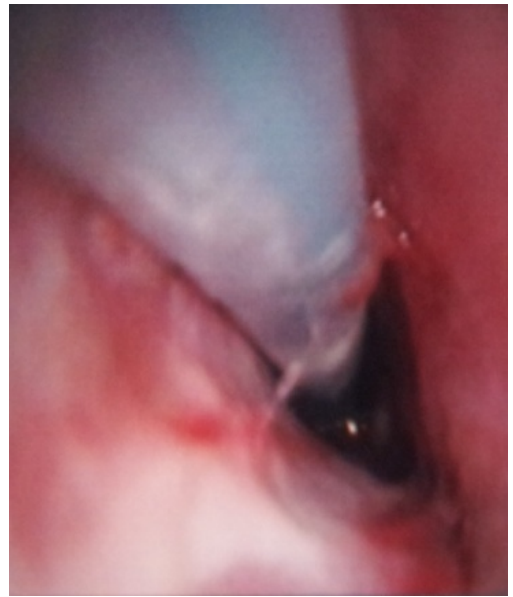

(c)

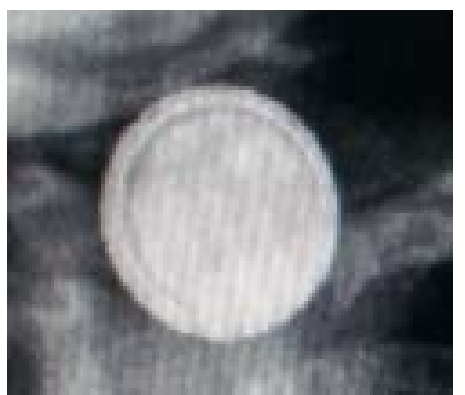

(b)

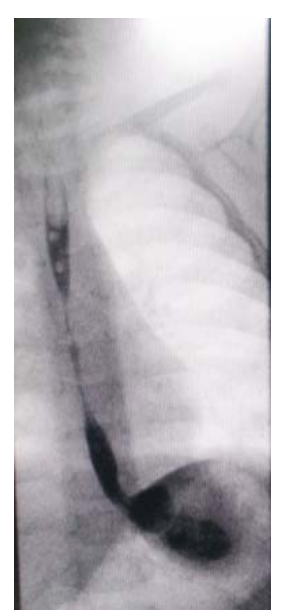

(d)
Figure 2. A 2-year-old male patient who swallowed a button battery. (a) Chest X-ray showing a button battery in the upper esophagus; (b) Magnified view showing details of the button battery; (c) Upper GI endoscopy showing non-circumferential pyogenic pseudomembranes $\sim 15 \mathrm{~cm}$ from the incisors; (d) Upper gastrointestinal contrast study showing a long stricture in the mid-esophagus that was managed with frequent endoscopic balloon dilatations.

body aspiration was witnessed in 11 of these patients, suspected because of symptoms in 5 patients, and reported by the patient in 1 case. Symptoms included breathing difficulty in 12 patients $(71 \%)$, coughing in 3 $(18 \%)$, wheezing in $2(12 \%)$, cyanosis in $1(6 \%)$, and fever in $1(6 \%)$. Most patients had more than one of these symptoms. Three patients $(26 \%)$ were asymptomatic at presentation. Eight patients (47\%) presented within 6 hours after the onset of symptoms, four (24\%) presented after 6 - 24 hours, and four (24\%) presented after 1 - 7 days. The distribution of symptoms according to the time of presentation is shown in Figure 3.

Physical examination revealed stridor in one patient, reduced air entry in five patients, desaturation requiring supplemental oxygen in one patient, and no abnormalities in nine patients. Posteroanterior chest X-ray findings were available in the records of all patients, and detected a metal FB in two patients, a foreign body in the trachea in one patient, hyperinflated lung(s) with no other findings in three patients, lung consolidation in three patients, a hyper-inflated lung with consolidation in one patient, and normal lung fields in one patient.

The aspirated FBs were blunt in 16 patients and sharp in 1 patient. Aspirated FBs were nuts in 10 patients, fava beans in two, a plastic button in two, a chicken bone in one, a sunflower seed in one, a needle in one, and a tissue in one. Bronchoscopic FB removal was successful in all patients.

The mean duration of endoscopic procedures was 30 min and the mean postoperative hospital stay was 1.4 days (range, $<1$ day to 6 days) (Figure 4).

\section{DISCUSSION}

\subsection{Presentation}

An accurate clinical history is important for the successful diagnosis and management of gastrointestinal and aspirated FBs. Most children are asymptomatic at the time of presentation. Common symptoms include drooling, gagging, dysphagia, odynophagia, decreased appetite, food refusal, fever, nausea, vomiting, hematemesis, rectal bleeding, neck pain, chest pain, abdominal pain, halitosis, cough, stridor, wheezing, and respiratory distress [11].

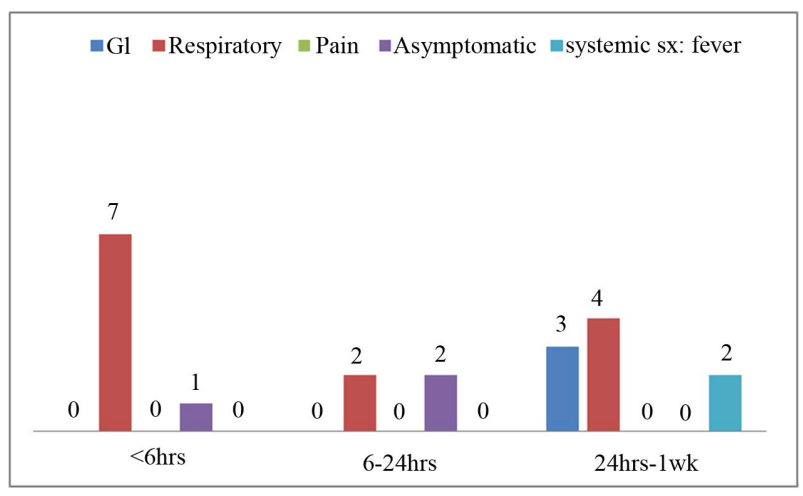

Figure 3. Symptoms in patients with tracheobronchial foreign bodies according to the duration of lodgment.

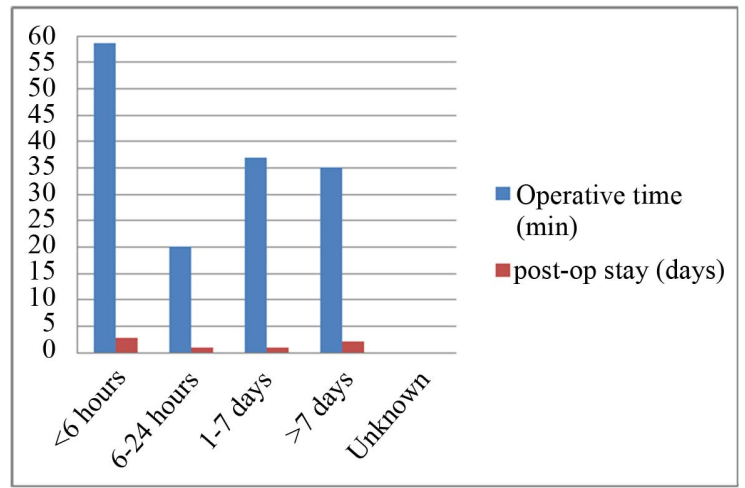

Figure 4. Mean procedure time and postoperative hospital stay according to the duration of foreign body lodgment in patients with tracheobronchial foreign bodies. 
Signs and symptoms associated with foreign body aspiration typically have three stages. First, there is choking followed by violent coughing, gagging, and possibly complete airway obstruction. Second, there is an asymptomatic interval after the reflexes become fatigued. The third stage is characterized by symptoms of complications [12]. Aspirated FBs should always be considered in children with unexplained recurrent pneumonia or other respiratory conditions that do not respond to appropriate treatment [13]. Symptoms of airway obstruction such as dyspnea and stridor also occur in approximately $10 \%$ of children with esophageal FBs [14].

The most common symptoms of FBs in the esophagus are laryngeal irritation, coughing, and choking caused by the highly compliant wall between the trachea and the esophagus [15].

Our clinical findings suggest that FB ingestion should be considered in children with signs and symptoms such as swallowing difficulty, features of airway compromise, and abdominal pain.

\subsection{Radiological Investigation}

A contrast-swallow study or endoscopic examination may identify such objects $[14,16]$. Other diagnostic methods such as ultrasonography and computerized tomography may also be helpful for diagnosing ingested non-radiopaque FBs $[17,18]$.

Although about $80 \%$ of aspirated FBs are radiolucent, some radiographic findings may assist in making a diagnosis. As the cross-sectional area of the airway increases during inspiration, air can pass beyond the FB. During expiration, the cross-sectional area of the airway decreases, and the air can become trapped [19]. Radiographic findings are less sensitive than history and physical examination for predicting bronchoscopy findings [20].

When the physical examination and X-ray findings are inconclusive, there is good evidence suggesting that using a combination of the two increases the diagnostic yield at 24 hours after aspiration [21].

\subsection{Types of FB}

\subsubsection{Coins}

Coins are the most frequently ingested FBs in children, and account for the majority of esophageal FBs. Coins typically get stuck in one of three locations. The thoracic inlet, defined as the area between the clavicles on chest $\mathrm{X}$-ray, is the site of transition of skeletal muscle to smooth muscle. At least $75 \%$ of retained coins get stuck at this site [22]. The other two sites are the mid-esophagus at the level of the aortic arch and carina, and the lower esophageal sphincter [11].
As $25 \%-30 \%$ of coins in the esophagus will pass spontaneously without complications, management of these patients may reasonably include a period of observation, in the range of 8 - 16 hours, particularly in asymptomatic older children and those with distally located coins $[19,23]$. It has been shown that glucagon is not effective in allowing coins to advance to the stomach in children [24]. It has been reported that coins located in the upper third, middle third, and lower third of the esophagus spontaneously pass to the stomach in $14 \%$, $43 \%$, and $67 \%$ of cases, respectively. Hamed et al. [25] reported a $94 \%$ success rate for removing coins from the esophagus using a Foley catheter. Coins in the stomach can safely be observed for up to 4 weeks. Coins less than $2.5 \mathrm{~cm}$ in diameter usually pass uneventfully. The parents should be instructed to inspect the stools for passage of the coin [11].

\subsubsection{Batteries}

Hearing aid batteries were the most commonly ingested type of battery in one pediatric study, with almost one third having come from the child's own device [26]. The majority of adverse outcomes occur in children younger than 4 years [27]. Batteries may cause injury by several mechanisms: 1) electrical discharge with hydrolysis and the creation of hydroxide ions in adjacent tissues causing mucosal burns, 2) necrosis due to direct pressure, 3) caustic injury due to alkalis (sodium or potassium hydroxide), and 4) mercury toxicity [26,27]. Esophageal necrosis, perforation, and death have been reported after button battery ingestion [17,26,28]. Although a large study found that mercury toxicity is rare [29], some batteries contain $5 \mathrm{~g}$ of mercuric oxide, which is a lethal dose. Lithium, manganese, and other heavy metals found in batteries do not cause toxicity [30,31].

Timely diagnosis and urgent removal are necessary for batteries located in the esophagus [28]. Button batteries may be misdiagnosed as coins on X-rays, but larger button batteries can be identified by the double contour around the edge [32]. Some authors state that gastric batteries typically pass through the remainder of the gastrointestinal tract without difficulty, with $80 \%$ passing within 48 hours [4]. This suggests that the batteries in the stomach only need to be removed if the patient is symptomatic or if the battery does not pass the pylorus within 48 hours, which may occur if it is larger than $15 \mathrm{~mm}$ in diameter $[1,4,33]$. Other physicians recommend that ingested batteries should be removed whenever possible $[10,34]$.

\subsubsection{Sharp and Large Objects}

Sharp and elongated FBs are responsible for 15\% - 35\% of perforations following FB ingestion and carry a significant risk of morbidity and mortality [17,35-37]. Per- 
foration is more likely with certain objects such as toothpicks, bones, razors, and long straight pins $[38,39]$. However, careful handling can result in safe removal. One patient in this study aspirated a pin, which was successfully removed by bronchoscopy (Figure 5).

Objects longer than $5 \mathrm{~cm}(3 \mathrm{~cm}$ in young children $)$ and wider than $2 \mathrm{~cm}$ are unlikely to pass through the gastrointestinal tract and should be removed endoscopically before they pass through the pylorus, if possible [11].

\subsection{Location}

The location of ingested FBs is an important factor in their management. We observed that FBs located in or above the upper third of esophagus were diagnosed earlier, and were more easily removed with significantly lower complication rates, compared with objects located in the lower third of the esophagus.

\subsection{Complications}

Both esophageal and aspirated FBs are associated with higher rates of adverse events when the diagnosis is delayed [40]. Tokar et al. [41] found that the relative risk of complications was $>1$ when the duration of lodgment was $>24$ hours, and increased to 6.83 when the duration was $>72$ hours. Early diagnosis and a safe retrieval method are important in order to avoid complications [19].

Complications from aspirated FBs include airway obstruction, stridor [42], bronchospasm, hypoxia, transient arrhythmias, and bradycardia. In a large series of 3300 patients, the mortality rate was reported to be less than $1 \%$ [43]. One of the patients in this series had an $80 \%$ obstruction of the subglottic airway after aspiration of a peanut (Figure 6)

Age-appropriate equipment is crucial in order to prevent further trauma to the respiratory epithelium. Operator familiarity with a wide assortment of laryngoscopes, bronchoscopes, and optical forceps facilitates the retrieval process and prevents unnecessary intraoperative

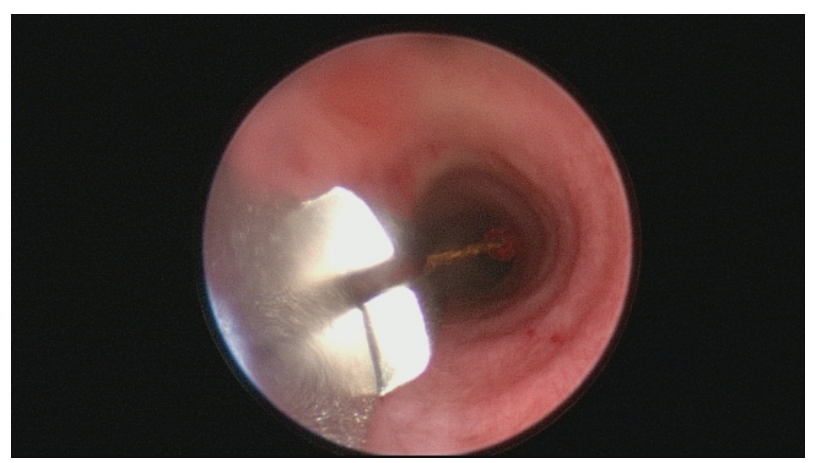

Figure 5. Bronchoscopic view showing safe removal of a needle from the left main bronchus.

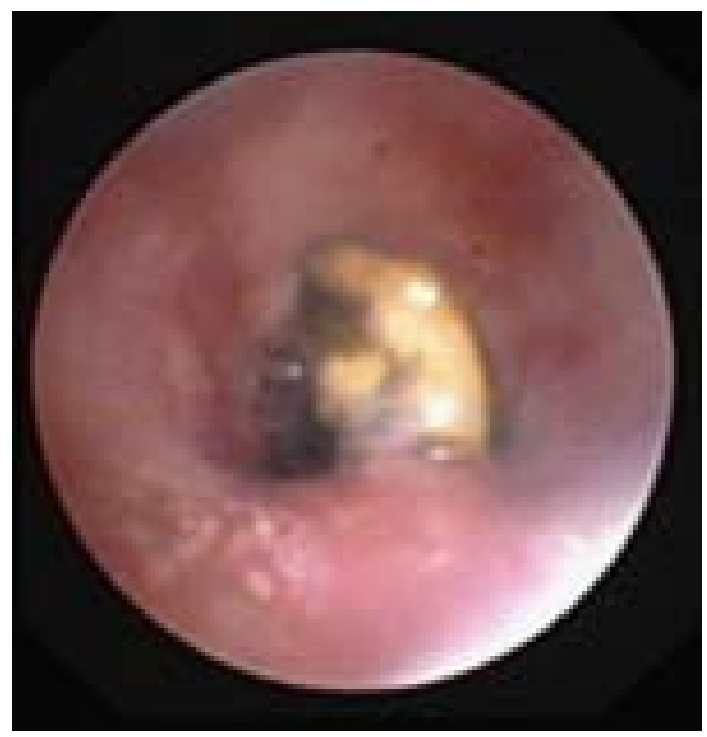

Figure 6. Bronchoscopic view of a peanut causing obstruction of about $80 \%$ of the airway, with surrounding erythema.

delays. There must always be two bronchoscopes available: one that is age-appropriate, and one that is a size smaller [19].

\subsection{Management Algorithm}

Based on our findings and review of the literature, we have developed a suggested algorithm for the future evaluation and management of children with radioopaque FB ingestion who present to our institution (Figure 7).

\subsection{Limitations}

This was a single-center study, with a relatively small number of patients with variable presentations, which limits the ability to generalize the results. Further multicenter studies are needed to confirm the findings, and to compare the characteristics of children in Qatar who present with FB ingestion with those in other countries.

\section{CONCLUSIONS}

In conclusion, coins were the most common gastrointestinal FBs and nuts were the most common tracheobronchial FBs. Diagnosis of FB ingestion was based on eye witness accounts, X-ray findings, and a high index of suspicion. X-rays should be performed in all cases of suspected FB ingestion.

Endoscopic removal under general anesthesia is safe and effective in children. We suggest an algorithm for the evaluation and management of children with suspected ingestion of a radio-opaque FB. The site, type, radio-opacity, and duration of lodgment of the FB affect 


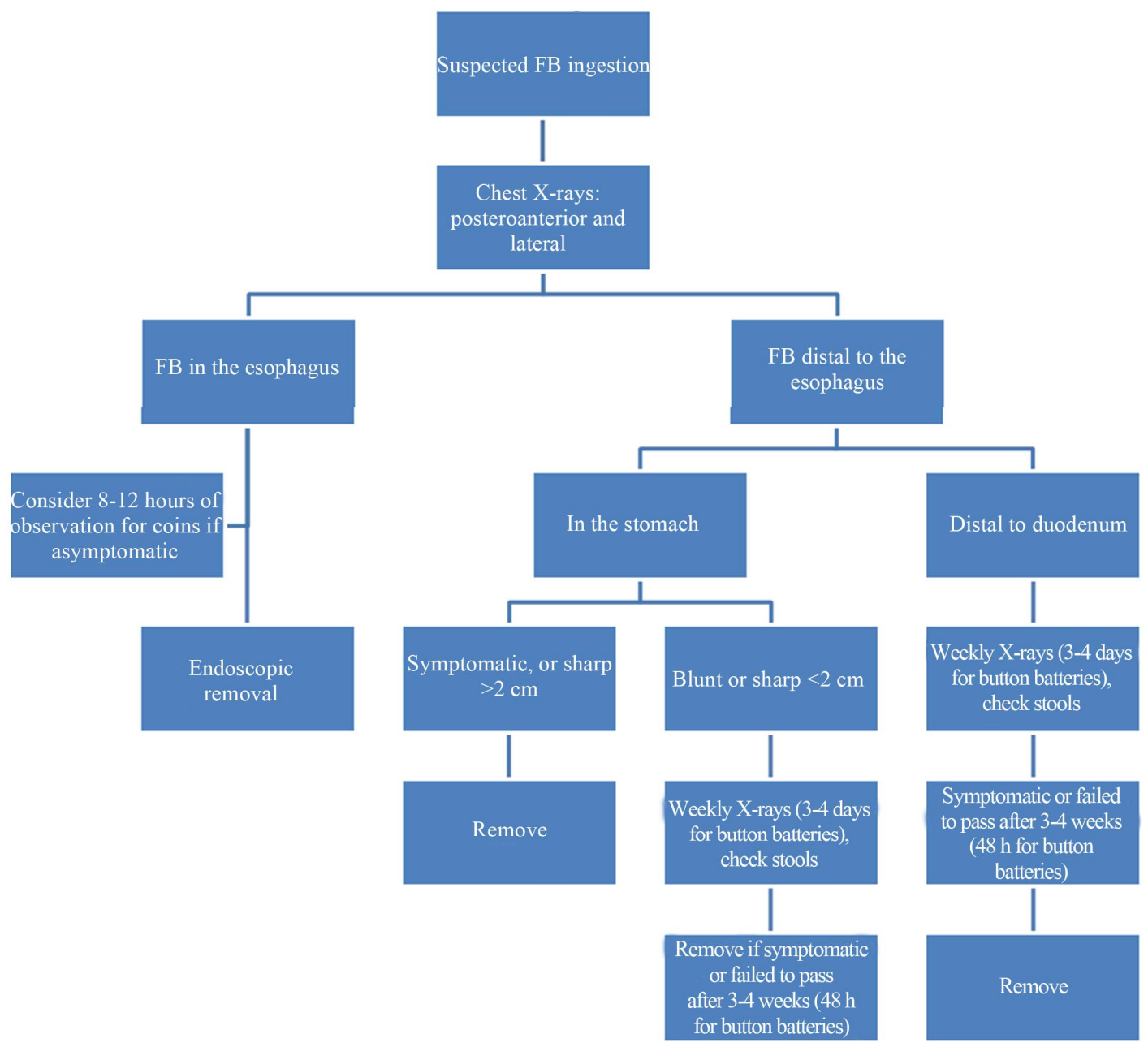

Figure 7. Suggested algorithm for the management of children with radio-opaque foreign body ingestion

outcome. Early diagnosis and appropriate management result in favorable outcomes.

\section{REFERENCES}

[1] Wahbeh, G., Wyllie, R. and Kay, M. (2002) Foreign body ingestion in infants and children: Location, location, location. Clinical Pediatrics, 41, 633-640. http://dx.doi.org/10.1177/000992280204100901

[2] Wai Pak, W., Chung Lee, W., Kwok Fung, H. and van Hasselt, C.A. (2001) A prospective study of foreign body ingestion in 311 children. International Journal of Pediatric Otorhinolaryngology, 58, 37-45. http://dx.doi.org/10.1016/S0165-5876(00)00464-X

[3] Gün, F., Salman, T., Abbasoglu, L., Celik, R. and Celik, A. (2003) Safety pin ingestion in children: A cultural fact. Pediatric Surgery International, 19, 482-484. http://dx.doi.org/10.1007/s00383-003-0964-y

[4] Kay, M. and Wyllie, R. (2005) Pediatric foreign bodies and their management. Current Gastroenterology Reports, 7, 212-218. http://dx.doi.org/10.1007/s11894-005-0037-6

[5] Dahshan, A. (2001) Management of ingested foreign bod- ies in children. Journal of the Oklahoma State Medical Association, 94, 183-186.

[6] Chen, M.K. and Beierle, E.A. (2001) Gastrointestinal foreign bodies. Pediatric Annals, 30, 736-742.

[7] Kim, J.K., Kim, S.S., Kim, J.I., Kim, S.W., Yang, Y.S., Cho, S.H., Lee, B.S., Han, N.I., Han, S.W., Chung, I.S., Chung, K.W. and Sun, H.S. (1999) Management of foreign bodies in the gastrointestinal tract: An analysis of 104 cases in children. Endoscopy, 31, 302-304. http://dx.doi.org/10.1055/s-1999-13

[8] Chaves, D.M., Ishioka, S., Félix, V.N., Sakai, P. and Gama-Rodrigues, J.J. (2004) Removal of a foreign body from the upper gastrointestinal tract with a flexible endoscope: A prospective study. Endoscopy, 36, 887-892. http://dx.doi.org/10.1055/s-2004-825856

[9] Yalçin, S., Karnak, I., Ciftci, A.O., Senocak, M.E., Tanyel, F.C. and Büyükpamukçu, N. (2007) Foreign body ingestion in children: An analysis of pediatric surgical practice. Pediatric Surgery International, 23, 755-761. http://dx.doi.org/10.1007/s00383-007-1958-y

[10] Arana, A., Hauser, B., Hachimi-Idrissi, S. and Vandenplas, Y. (2001) Management of ingested foreign bodies in childhood and review of the literature. European Journal 
of Pediatrics, 160, 468-472. http://dx.doi.org/10.1007/s004310100788

[11] Hesham, A. and Kader, H. (2010) Foreign body ingestion: Children like to put objects in their mouth. World Journal of Pediatrics, 6, 301-310. http://dx.doi.org/10.1007/s12519-010-0231-y

[12] Ozguner, I.F., Buyukyavuz, B.I., Savas, C., Yavuz, M.S. and Okutan, H. (2004) Clinical experience of removing aerodigestive tract foreign bodies with rigid endoscopy in children. Pediatric Emergency Care, 20, 671-673. http://dx.doi.org/10.1097/01.pec.0000142951.65888.fb

[13] Harris, C.S., Baker, S.P., Smith, G. and Harris, R.M. (1984) Childhood asphyxiation by food: A national analysis and overview. JAMA, 251, 2231-2235. http://dx.doi.org/10.1001/jama.1984.03340410039029

[14] Crysdale, W.S., Sendi, K.S. and Yoo, J. (1991) Esophageal foreign bodies in children: 15-year review of 484 cases. Annals of Otology, Rhinology, and Laryngology, 100, 320324.

[15] Friedman, E.M. (2000) Tracheobronchial foreign bodies. Otolaryngologic Clinics of North America, 33, 179-185. http://dx.doi.org/10.1016/S0030-6665(05)70214-0

[16] Healy, G.B. (1991) Aerodigestive tract foreign bodies. In: Fallis, J.C., Filler, R.M. and Lemoine, G., Eds., Pediatric Thoracic Surgery, Elsevier, New York, 192-200.

[17] Stack, L.B. and Munter, D.W. (1996) Foreign bodies in the gastrointestinal tract. Emergency Medicine Clinics of North America, 14, 493-521. http://dx.doi.org/10.1016/S0733-8627(05)70264-9

[18] Newman, B. and Girdany, B.R. (1990) Gastric trichobezoars-Sonographic and computed tomographic appearance. Pediatric Radiology, 20, 526-527. http://dx.doi.org/10.1007/BF02011382

[19] Digoy, G.P. (2008) Diagnosis and management of upper aerodigestive tract foreign bodies. Otolaryngologic Clinics of North America, 41, 485-496, vii-viii. http://dx.doi.org/10.1016/j.otc.2008.01.013

[20] Ciftci, A.O., Bingöl-Koloğlu, M., Senocak, M.E., Tanyel, F.C. and Büyükpamukçu, N. (2003) Bronchoscopy for evaluation of foreign body aspiration in children. Journal of Pediatric Surgery, 38, 1170-1176. http://dx.doi.org/10.1016/S0022-3468(03)00263-X

[21] Tokar, B., Ozkan, R. and Ilhan, H. (2004) Tracheobronchial foreign bodies in children: Importance of accurate history and plain chest radiography in delayed presentation. Clinical Radiology, 59, 609-615. http://dx.doi.org/10.1016/j.crad.2004.01.006

[22] Webb, C.V. (1995) Management of foreign bodies of the upper gastrointestinal tract: Update. Gastrointestinal Endoscopy, 41, 4139-4149. http://dx.doi.org/10.1016/S0016-5107(95)70274-1

[23] Waltzman, M.L., Baskin, M., Wypij, D., Mooney, D., Jones, D. and Fleisher, G. (2003) A randomized clinical trial of the management of esophageal coins in children [see comment]. Pediatrics, 116, 614-619. http://dx.doi.org/10.1542/peds.2004-2555

[24] Mehta, D., Attia, M., Quintana, E. and Cronan, K. (2001) Glucagon use for esophageal coin dislodgment in chil- dren: A prospective, double-blind, placebo-controlled trial. Academic Emergency Medicine, 8, 200-203.

http://dx.doi.org/10.1111/j.1553-2712.2001.tb01291.x

[25] Caravati, E.M., Bennett, D.L. and McElwee, N.E. (1989) Pediatric coin ingestion. A prospective study on the utility of routine roentgenograms. American Journal of Diseases of Children, 143, 549-551. http://dx.doi.org/10.1001/archpedi.1989.02150170047018

[26] Litovitz, T. and Schmitz, B.F. (1992) Ingestion of cylindrical and button batteries: An analysis of 2382 cases. Pediatrics, 89, 747-757.

[27] Litovitz, T., Whitaker, N., Clark, L., White, N.C. and Marsolek, M. (2010) Emerging battery ingestion hazard: Clinical implications. Pediatrics, 125, 1168-1177. http://dx.doi.org/10.1542/peds.2009-3037

[28] Samad, L., Ali, M. and Ramzi, H. (1999) Button battery ingestion: Hazards of esophageal impaction. Journal of Pediatric Surgery, 34, 1527-1531. http://dx.doi.org/10.1016/S0022-3468(99)90119-7

[29] Yardeni, D., Yardeni, H., Coran, A.G. and Golladay, E.S. (2004) Severe esophageal damage due to button battery ingestion: Can it be prevented? Pediatric Surgery International, 20, 496-501. http://dx.doi.org/10.1007/s00383-004-1223-6

[30] Bass, D.H. and Millar, A.J. (1992) Mercury absorption following button battery ingestion. Journal of Pediatric Surgery, 27, 1541-1542. http://dx.doi.org/10.1016/0022-3468(92)90500-7

[31] Temple, D.M. and McNeese, M.C. (1983) Hazards of battery ingestion. Pediatrics, 71, 100-103.

[32] Chung, S., Forte, V. and Campisi, P. (2010) A review of pediatric foreign body ingestion and management. Clinical Pediatric Emergency Medicine, 11, 225-230. http://dx.doi.org/10.1016/j.cpem.2010.06.002

[33] Louie, M.C. and Bradin, S. (2009) Foreign body ingestion and aspiration. Pediatrics in Review, 30, 295-301.

[34] Hachimi-Idrissi, S., Corne, L. and Vandenplas, Y. (1998) Management of ingested foreign bodies in childhood: Our experience and review of the literature. European Journal of Emergency Medicine, 5, 319-323. http://dx.doi.org/10.1097/00063110-199809000-00007

[35] Pinero Madrona, A., Fernández Hernández, J.A., Carrasco Prats, M., Riquelme Riquelme, J. and Parrila Paricio, P. (2000) Intestinal perforation by foreign bodies. European Journal of Surgery, 166, 307-309. http://dx.doi.org/10.1080/110241500750009140

[36] Abel, R.M., Fischer, J.E. and Hendren, W.H. (1971) Penetration of the alimentary tract by a foreign body with migration to the liver. Archives of Surgery, 102, 227-229. http://dx.doi.org/10.1001/archsurg.1971.01350030065021

[37] Kountouras, J., Chatzopoulos, D. and Vrettos, M. (2001) Perforation of midpart of ileum caused by entrapment of a large, wide foreign body. Annals of Gastroenterology, 14, 329-332.

[38] Steenvoorde, P., Moues, C.M. and Viersma, J.H. (2002) Gastric perforation due to the ingestion of a hollow toothpick: Report of a case. Surgery Today, 32, 731-733.

[39] Maleki, M. and Evan, W.E. (1970) Foreign-body perfora- 
tion of the intestinal tract. Report of 12 cases and review of the literature. Archives of Surgery, 101, 475-477. http://dx.doi.org/10.1001/archsurg.1970.01340280027008

[40] Chaikhouni, A., Kratz, J.M. and Crawford, F.A. (1985) Foreign bodies of the esophagus. The American Surgeon, 51, 173-179.

[41] Tokar, B., Cevik, A.A. and Ilhan, H. (2007) Ingested gastrointestinal foreign bodies: Predisposing factors for complications in children having surgical or endoscopic removal. Pediatric Surgery International, 23, 135-139. http://dx.doi.org/10.1007/s00383-006-1819-0

[42] Zerella, J.T., Dimler, M., McGill, L.C. and Pippus, K.J.
(1998) Foreign body aspiration in children: Value of radiography and complications of bronchoscopy. Journal of Pediatric Surgery, 33, 1651-1654. http://dx.doi.org/10.1016/S0022-3468(98)90601-7

[43] Sersar, S.I., Rizk, W.H., Bilal, M., El Diasty, M.M., Eltantawy, T.A., Abdelhakam, B.B., Elgamal, A.M. and Bieh, A.A. (2006) Inhaled foreign bodies: Presentation, management and value of history and plain chest radiography in delayed presentation. Otolaryngology-Head and Neck Surgery, 134, 92-99.

http://dx.doi.org/10.1016/j.otohns.2005.08.019 